\title{
O PIBID NO COTIDIANO ESCOLAR: UMA PESQUISA SOBRE AS REPRESENTAÇÕES DE DIRETORES E PROFESSORES EM UBERABA, MG.
}

\author{
Vera Lúcia Bonfim Tiburzio (vlbonfim@gmail.com, ICENE, UFTM). \\ Amanda Regina Gonçalves (IELACHS, UFTM). \\ Natalia Aparecida Morato Fernandes (IELACHS, UFTM).
}

\section{RESUMO}

Este trabalho, apoiado pela FAPEMIG, apresenta resultados parciais de uma pesquisa sobre os impactos do PIBID sobre o cotidiano de escolas de Uberaba-MG. Os dados foram obtidos com questionários, entrevistas e grupos focais tendo como sujeitos diretores, professores e alunos de escolas parceiras do PIBID e pela análise de documentos que expressam as representações dos sujeitos envolvidos no programa. Nos questionários aplicados a diretores e professores de 12 escolas foi identificado que estes perceberam mudanças na rotina das escolas a partir do PIBID, destacando o maior engajamento dos alunos participantes em atividades escolares e o aumento da motivação e interesse destes pelas aulas. Os professores destacam como principal resultado do PIBID o acesso à formação continuada, enquanto para os diretores as principais mudanças na prática docente são a melhora no relacionamento com os alunos, a diversificação da metodologia utilizada em sala de aula e a ampliação do domínio de conteúdo. Podemos concluir que o PIBID tem promovido mudanças positivas no que diz respeito à dinamização do cotidiano escolar, com a introdução de novas atividades, a melhora na prática docente, a busca por formação continuada, o maior envolvimento dos alunos nas atividades e a maior motivação e interesse destes pelas aulas.

Palavras-chave: PIBID, Cotidiano Escolar, Formação Docente.

\section{INTRODUÇÃO}

O Programa Institucional de Bolsas de Iniciação à Docência (PIBID) é um programa financiado pela CAPES que visa induzir e fomentar a formação inicial e continuada de profissionais do magistério (Lei $\mathrm{n}^{\circ} 11.502$, de 11 de julho de 2007). Dentre as suas principais metas, duas focalizam aspectos importantes da escola básica: a) Promover a melhoria da qualidade da educação básica e b) Articular e integrar a educação superior e a educação básica do sistema público de ensino.

Na região de Uberaba, no Triângulo Mineiro, o PIBID começou com o projeto institucional da UFTM aprovado em 2009, seguido por um segundo projeto institucional aprovado na mesma IES em 2011. Nesta mesma época também foram aprovados projetos de iniciação à docência no IFTM e na Universidade de Uberaba, esta última uma instituição privada. Em 2013, foi apresentado o terceiro projeto institucional do PIBID UFTM, do qual participam todos os cursos de licenciatura da UFTM, perfazendo dez subprojetos e aproximadamente 430 bolsistas entre coordenadores institucionais, de gestão e de área, supervisores e licenciados e abrangendo as áreas de Química, Física, Matemática, História, Geografia, Ciências Biológicas, Língua Portuguesa, Língua Inglesa, Língua Espanhola e Interdisciplinar. Os subprojetos são 


\section{SEMINÁRIO DE PESQUISA EM CIÊNCIAS HUMANAS - SEPECH \\ Humanidades, Estado e desafios didático-científicos \\ Londrina, 27 a 29 de julho de 2016}

desenvolvidos em cerca de 30 escolas públicas estaduais e municipais de ensino fundamental e médio, atingindo aproximadamente 5.000 alunos.

Dada a dimensão alcançada pelo PIBID em Uberaba e região, tornou-se premente a necessidade de se obter dados sistemáticos a respeito do programa. Nesse sentido foi proposta a pesquisa "Impactos das ações do PIBID nas escolas de UberabaMG" por um grupo de professores vinculados ao PIBID UFTM, com o objetivo de "fazer um diagnóstico e analisar os impactos das ações do Programa Institucional de Bolsas de Iniciação à Docência nas escolas de Uberaba, na região do Triângulo Mineiro" (BARBOSA, 2013). Com este estudo pretende-se contribuir com elementos para que as IES executoras do programa possam planejar mais adequadamente seus projetos, e, de modo mais amplo, para que os resultados da pesquisa possam contribuir para nortear a CAPES quanto a efetividade das políticas implementadas. Visando discutir o impacto das ações do PIBID nas escolas de Uberaba por meio das representações de diretores, professores e alunos das escolas públicas que receberam o programa, a pesquisa adota como instrumentos de obtenção de dados a aplicação de questionários, a realização de entrevistas semi-estruturadas e a realização de grupos focais, além da análise de relatórios produzidos no âmbito do PIBID.

No presente artigo serão apresentados e discutidos dados preliminares obtidos dos questionários supracitados, os quais tiveram como sujeitos diretores, professores e alunos de escolas parceiras do PIBID. Os resultados obtidos a partir das entrevistas e grupos focais estão em fase de sistematização e análise e serão apresentados em oportunidades futuras.

\section{REPRESENTAÇÕES DE SUJEITOS ESCOLARES SOBRE O PIBID: ANÁLISE DE RESULTADOS.}

Os diretores das escolas parceiras do PIBID em Uberaba-MG fizeram parte dos sujeitos desta pesquisa, uma vez que a gestão envolve o trabalho de coordenação e acompanhamento do trabalho na escola. O questionário foi aplicado a oito diretores, de um total de doze escolas públicas estaduais ou municipais em Uberaba que participaram da pesquisa. Com vinte e oito perguntas, o questionário foi dividido em duas partes, sendo que na primeira buscou-se levantar informações sobre o perfil dos gestores e na segunda sobre as perspectivas destes quanto aos impactos do PIBID nas escolas parceiras. A seguir, apresentamos alguns resultados obtidos a partir da sistematização das respostas dos diretores.

O reconhecimento preliminar do perfil dos diretores entrevistados demonstra que a maioria $(62,5 \%)$ é mulher. A faixa de idade de $50 \%$ dos entrevistados é de 50 a 65 anos, enquanto $38 \%$ tem de 35 a 49 anos e apenas um deles possui entre 25 a 34 anos. Quanto à formação, a maioria (aproximadamente 63\%) se graduou em escola particular e possui especialização. $25 \%$ dos diretores são graduados em matemática, $12 \% \mathrm{em}$ português, $13 \%$ em geografia, mas a metade dos entrevistados é formada em outras áreas que não as específicas de uma disciplina do currículo da educação básica. 62,5\% dos entrevistados atua em escola pública estadual e 37,5\% em pública municipal, sendo que 12,5\% também trabalham em escola particular. Quanto à carga horária de trabalho semanal, a maioria possui carga total maior que 40 horas, sendo que os demais se dividem em até 10 horas ou de 31 a 40 horas por semana. Seis dos oito diretores 


\section{SEMINÁRIO DE PESQUISA EM CIÊNCIAS HUMANAS - SEPECH \\ Humanidades, Estado e desafios didático-científicos \\ Londrina, 27 a 29 de julho de 2016}

entrevistados atuam no magistério há mais de 25 anos, sendo que metade deles atua na gestão escolar há 5 anos ou menos; dois atuam entre 11 a 15 anos; um deles atua entre 6 a 10 anos e outro há mais de 20 anos. Cerca de 40\% dos entrevistados começaram a atuar na gestão escolar após mais de 20 anos de docência.

Podemos analisar o perfil dos diretores de escola entrevistados a partir de estudos que indicam tendências gerais do "ciclo de vida" dos professores, como os realizados por Michaël Huberman (1992, p. 38) que apontam que "o desenvolvimento da carreira é, assim, um processo e não uma série de acontecimentos". Ainda que nunca para a totalidade de professores, este autor delimitou "sequências" ou "maxitipos" referentes a organização da carreira em fases ou estágios.

$\mathrm{O}$ perfil dos diretores levantado em nossa pesquisa demonstra que, em sua maioria, a escolha e atuação na direção escolar se dá nas sequências, conforme Huberman (1992), de "exploração" e de "estabilização". Considerando que a maioria atua no magistério há mais de 25 anos e que a atuação na direção se deu, também para cerca de $38 \%$, após vinte anos na profissão, podemos entender que a escolha pela direção trata-se da experimentação de um novo papel num período exploratório da profissão. Já o fato de manter-se na função de direção por longos períodos (até 20 anos ou mais) significa, segundo este autor, que a fase de exploração foi positiva e passou-se para a fase de estabilização:

\footnotetext{
"Se esta fase for globalmente positiva, passa-se a uma fase de "estabilização", ou de compromisso, na qual as pessoas centram a sua atenção no domínio das diversas características do trabalho, na procura de um setor de focalização ou de especialização, na aquisição de um caderno de encargos e de condições de trabalho satisfatórias e, em vários casos, na tentativa de desempenhar papéis e responsabilidades de maior importância ou prestígio, ou mais lucrativas" (HUBERMAN, 1992, p. 37).
}

Assim, podemos entender que atuar na direção da escola representa assumir um cargo de maior responsabilidade, bem como de maior prestígio e, também, mais rentável dentro do sistema escolar brasileiro. Ao mesmo tempo que as características de experimentação e diversificação da fase de estabilização observadas pelo autor também podem explicar a decisão da direção em inserir a escola que dirige em programas como o PIBID ou, ao menos, aceitar a participação de professores do quadro docente da instituição que dirige nestes. Portanto, entende-se o fato de assumirem o cargo de direção escolar como parte de uma "busca de novos desafios", numa fase em que estariam mais motivados, sendo que tal motivação traduzir-se-ia em "ambição pessoal (...), através do acesso a postos administrativos" (PRICK, 1986 apud HUBERMAN, 1992, p. 42).

Quanto à percepção dos diretores sobre os impactos do PIBID na escola, todos os diretores responderam ter percebido mudanças na rotina da escola a partir da introdução do PIBID, sendo que a maioria deles (aproximadamente 63\%) indicou como mudança mais importante a inclusão de novas atividades no calendário escolar, seguido da ampliação das atividades extra turno e da ampliação da utilização dos espaços da escola. 


\section{SEMINÁRIO DE PESQUISA EM CIÊNCIAS HUMANAS - SEPECH \\ Humanidades, Estado e desafios didático-científicos \\ Londrina, 27 a 29 de julho de 2016}

Das escolas que participaram da pesquisa $80 \%$ não destinam um espaço específico para as atividades do PIBID. Os espaços da escola mais utilizados para

atividades do PIBID, segundo os diretores, são a sala de aula, o pátio, a sala de multimeios e a biblioteca. Além destes também foram indicados o laboratório de ciências, a sala de informática e a quadra.

Quase a totalidade de diretores entrevistados (87,5\%) afirmou que houve maior procura dos professores por ações/projetos de capacitação profissional após a parceria entre PIBID e sua escola, sendo que a metade destes indicou como ação/projeto que tem sido mais procurado pelos professores a participação em grupos de estudo ou de pesquisa e 37,5\% deles também indicou a participação em congressos e eventos acadêmicos ou da área educacional e também em cursos de formação continuada.

As respostas acima representam dilemas frequentes na gestão escolar, que precisa lidar com a necessidade e importância da formação continuada dos professores mesmo sabendo que esta geralmente implica na ausência dos mesmos na sala de aula. Com poucas (as vezes nenhuma) alternativas oferecidas pelos órgãos públicos para lidar com tal situação, a direção encontra-se frequentemente no difícil papel de administrar a presença de turmas de alunos sem professor na escola. Este limitação gera, em muitos casos, dificuldades de liberação do professor para participar de ações/projetos formativos que necessitem de sua ausência na escola. Diante desta realidade, a evidência citada pelos gestores do aumento da procura dos professores por ações e projetos de capacitação profissional após a parceria entre o PIBID e as escolas demonstra a relevância deste impacto do programa no cotidiano escolar, bem como um significativo papel do programa na formação continuada dos professores. Este aspecto é destacado na Carta de Uberaba, emitida no IV Encontro Nacional das Licenciaturas ENALIC e III Seminário nacional do PIBID, ocorrido em Uberaba-MG, no ano de 2013, que sinaliza como uma das expectativas e necessidades dos docentes:

\footnotetext{
"Uma formação continuada que atenda às necessidades formativas dos professores na qual eles possam, efetivamente, aprofundar-se nos conhecimentos de sua área específica, sem desconsiderar os modos e condições (formação pedagógica) necessários para que este conteúdo possa ser aprendido. Que os professores tenham tempo destinado a esta formação, com estrutura adequada na própria escola, incluída na sua carga horária normal de trabalho e sejam remunerados para isso. Que possam participar de cursos ofertados por instituições de excelência, especialmente em programas de pós-graduação lato e stricto sensu. Que estados e municípios incentivem e possibilitem essa formação liberando seus professores ou computando a carga horária de formação na carga horária de trabalho" (CARTA DE UBERABA, 2015, p. 409).
}

Questionados sobre quais mudanças ocorreram na prática docente dos supervisores do PIBID, considerando que um diretor não respondeu a pergunta e outro indicou como pergunta que não se aplicava, os demais responderam que ocorreu melhora do relacionamento com os alunos, diversificação da metodologia utilizada em sala de aula e ampliação do domínio de conteúdo. A pesquisa também constatou ainda que, na percepção da maioria dos diretores $(87,5 \%)$, a condição de bolsista não gera conflito nas relações entre professores. A maioria dos diretores também respondeu que os professores não participantes do PIBID se engajam nas atividades propostas pelos 


\section{SEMINÁRIO DE PESQUISA EM CIÊNCIAS HUMANAS - SEPECH \\ Humanidades, Estado e desafios didático-científicos \\ Londrina, 27 a 29 de julho de 2016}

supervisores, principalmente por meio da participação na execução das atividades. Interessantemente, esta percepção contradiz a dos supervisores que participaram da

pesquisa, dos quais 79\% responderam que percebem como "pouco" o envolvimento dos outros professores da escola em relação ao PIBID.

Para quase todos os diretores entrevistados houve mudanças no desempenho dos alunos da escola nas avaliações externas depois que o PIBID passou a atuar na escola, principalmente nas avaliações Prova Brasil e SIMAVE, mas também foram citadas avaliações como Provinha Brasil, por cerca de 30\% dos entrevistados, e PISA, por cerca de $10 \%$ deles ${ }^{1}$. Ainda que esta constatação esteja de acordo com uma das intenções do PIBID, ligada à "melhoria do ensino nas escolas públicas em que o Índice de Desenvolvimento da Educação Básica (Ideb) esteja abaixo da média nacional, de 4,4" (BRASIL, 2011), tais avaliações têm sido foco de intensos questionamentos por parte dos sujeitos escolares e de estudiosos do campo da educação. Estas avaliações compõem um quadro descrito por Libâneo et. al. (2012) como parte de um sistema educacional que tem servido para controle e regulação por parte do Estado e como mecanismo de introdução da lógica de mercado, visando competição e reforçando valores como individualismo, meritocracia e competência:

“[...] a avaliação educacional em larga escala faz parte das políticas que vêm sendo desenvolvidas em vários países desde os anos 80 do século $\mathrm{XX}$, por meio de testes estandartizados, com ênfase nos resultados ou produtos educacionais. (...) com o objetivo de aferir o desempenho dos alunos nos diferentes graus de ensino, a fim de controlar a qualidade do ensino ministrado nas escolas brasileiras" (LIBÂNEO et. al., 2012, p. 263).

O principal instrumento de avaliação sistêmica nacional foi instituído no Brasil em 1994, por meio do Sistema Nacional de Avaliação da Educação Básica (Saeb), sendo composto por dois processos: a Avaliação Nacional da Educação Básica (Aneb) e a Avaliação Nacional do Rendimento Escolar (Anresc), desenvolvidos pelo Instituto Nacional de Estudos e Pesquisas Educacionais Anísio Teixeira (Inep), autarquia do Ministério da Educação (MEC). Considerando que estes instrumentos se realizam no cotidiano da escola e da sala de aula, o diretor da escola encontra-se num complexo

1 A Avaliação Nacional do Rendimento Escolar (Anresc), também conhecida como Prova Brasil, é uma avaliação complementar ao Sistema Nacional de Avaliação da Educação Básica e um dos componentes para o cálculo do Índice de Desenvolvimento da Educação Básica (Ideb). Ocorre de forma censitária bianualmente e envolvendo os alunos do $5^{\circ}$ ano e $9^{\circ}$ ano do Ensino Fundamental das escolas públicas brasileiras. A Avaliação da Alfabetização Infantil (Provinha Brasil) avalia à alfabetização e o letramento em Língua Portuguesa e Matemática, em crianças matriculadas no $2^{\circ}$ ano do Ensino Fundamental das escolas públicas brasileiras. O Programa Internacional de Avaliação de Estudantes (PISA) é uma avaliação aplicada a estudantes na faixa dos 15 anos e produz resultados comparáveis entre diversos países. É desenvolvido e coordenado pela Organização para Cooperação e Desenvolvimento Econômico (OCDE), sendo coordenado no Brasil pelo Inep (Inep, 2016). Já o Sistema Mineiro de Avaliação da Educação Pública (SIMAVE) consiste em duas modalidades complementares de avaliação coordenados pela Secretaria de Estado de Educação de Minas Gerais: o Programa de Avaliação da Aprendizagem Escolar (PAAE), que consiste em uma avaliação interna da escola e o Programa de Avaliação da Alfabetização (PROALFA) e o Programa de Avaliação da Rede Pública de Educação Básica (PROEB), que são modalidades de avaliação externa do sistema de ensino (Minas Gerais, 2016). 


\section{SEMINÁRIO DE PESQUISA EM CIÊNCIAS HUMANAS - SEPECH \\ Humanidades, Estado e desafios didático-científicos \\ Londrina, 27 a 29 de julho de 2016}

papel fronteiriço "entre decisões do sistema de ensino e sua efetivação nas escolas revela claramente que as formas de organização e gestão desempenham um papel

educativo, já que dão certa conformação às atitudes, ideias e modos de agir tanto de professores como de alunos" (LIBÂNEO et. al., 2012, p. 416). Sobre isso os autores assinalam tanto a responsabilidade das Secretarias de Educação de "fazer as escolas funcionarem e, para isso, precisam que os professores tomem conhecimento de certas normas e diretrizes", mas também assinalam "a necessidade de atitude crítica ante as determinações oficiais, para avaliar o grau em que as políticas e diretrizes são democráticas, justas, inclusivas, respeitadoras das diferenças relativas ao direito de todos à escolarização" (idem, p. 417). Neste contexto, o questionário aplicado aos diretores também levantou informações sobre as percepções quanto aos impactos do PIBID além daqueles sobre as avaliações sistêmicas. Assim, 87,5\% dos diretores notaram alguma mudança no comportamento dos alunos (participantes ou não) depois que o PIBID passou a atuar na escola, sendo a mai citada o aumento da motivação e interesse dos alunos pelas aulas (50\%), seguida pelo engajamento em atividades da escola, melhoras no desempenho e valorização da escola (37,5\% cada). As respostas sobre diminuição da evasão, melhora do desempenho nas notas e melhora em relação à disciplina foram mencionadas apenas por $12,5 \%$ dos diretores cada.

Quarenta professores de 12 escolas parceiras do PIBID em Uberaba-MG também participaram como sujeitos desta pesquisa. Destes, 60\% nunca atuaram como bolsistas do PIBID, 32,5\% atuam ou já atuaram como supervisores e $7,5 \%$ já atuaram como bolsistas de iniciação à docência, quando ainda eram licenciandos. O questionário aplicado aos professores foi composto por 34 questões organizadas em duas partes, sendo a primeira relativa ao perfil do entrevistado, sua formação e atuação profissional e a segunda relacionada aos impactos do PIBID nas escolas.

Do total de professores respondentes, a maioria (75\%) considera que as atividades do PIBID impactaram positivamente na mudança de atitudes $e$ comportamentos dos alunos que participaram das atividades. As mudanças foram percebidas principalmente na diminuição da evasão (57\%), aumento na assiduidade (55\%), maior engajamento dos alunos nas atividades das escolas (47,5\%), aumento da motivação e interesse dos alunos pelas aulas (também 47,5\%), melhora nas disciplinas escolares (33\%) e melhor desempenho nas avaliações (melhores notas - 25\%) dados que corroboram de modo geral a visão dos diretores sobre o assunto. Para 57,5\% dos professores participantes da pesquisa o PIBID contribuiu ainda para a ampliação do interesse dos alunos pelo ingresso futuro numa universidade pública.

Com relação a se o PIBID contribui para a aproximação entre a escola e a comunidade, as respostas dadas pelos professores nos questionários se dividiram, sendo que metade afirma que o PIBID contribuiu muito para essa aproximação e a outra metade afirma que contribuiu pouco. Neste contexto, essa temática será investigada de forma mais aprofundada futuramente, também por meio de outros instrumentos mobilizados nesta pesquisa, a fim de se obter um quadro mais claro sobre esta contribuição. Por hora, consideramos a hipótese que a percepção quanto a aproximação entre escola e comunidade motivada pelo PIBID depende muito das características das atividades dos diferentes conjuntos de subprojetos que atuavam em cada escola, especialmente no que diz respeito ao maior ou menor envolvimento com a comunidade externa promovido pelas diferentes atividades dos diferentes subprojetos. 


\section{SEMINÁRIO DE PESQUISA EM CIÊNCIAS HUMANAS - SEPECH \\ Humanidades, Estado e desafios didático-científicos \\ Londrina, 27 a 29 de julho de 2016}

$75 \%$ daqueles professores que participaram como supervisores afirmaram que a formação continuada e a possibilidade de apresentarem trabalhos em eventos científicos foram as motivações mais relevantes para atuar no PIBID, enquanto menos de $10 \%$

relataram a contribuição na formação dos licenciandos como o motivo para participarem. O PIBID tem como um dos seus objetivos aproximar os supervisores da universidade e das atividades desenvolvidas neste espaço. No entanto, notamos que a maioria deles não se sente co-formador dos futuros professores, mas veem como interessante para si próprios a formação continuada. Curiosamente, $93 \%$ deles consideram que a participação em atividades do PIBID impactam muito positivamente a formação docente dos licenciandos, mesma proporção que consideram que o PIBID proporcionou a possibilidade de refletir sobre a sua própria prática docente a partir de alguma atividade desenvolvida. 53,5\% dos supervisores não possuíam experiência anterior como orientador de licenciandos enquanto $46,5 \%$ já possuíam.

Ainda para esse grupo de supervisores, 90\% considera que as atividades do PIBID impactaram positivamente na aprendizagem de conteúdos escolares pelos alunos que participaram do projeto e apenas $9,3 \%$ afirmam que esse impacto foi pequeno. De acordo com os dados coletados, as atividades que mais impactaram na aprendizagem do conteúdo escolar pelos alunos foram intervenção em sala de aula com a participação dos licenciandos e supervisores, com $69,7 \%$ de menções, atividades extra classe, oficinas e minicursos, cada uma com $62,7 \%$ de menções e feiras de conhecimento (gincana, exposição) e trabalhos fora do ambiente escolar (visitas etc.), com 55,8\% de menções.

Uma questão que inquietava bastante aos membros desta equipe de pesquisa é conhecer como é a relação entre os supervisores e os demais professores da escola que não participam do PIBID. Para $86 \%$ dos supervisores, há pouco envolvimento dos outros professores da escola que não participam do PIBID em relação as atividades do programa desenvolvidas pelos colegas bolsistas. No entanto $81,3 \%$ deles percebem muito envolvimento da direção em relação as atividades do PIBID. Estes dados sugerem que a gestão escolar aprova e apoia as atividades do PIBID enquanto os demais professores não bolsistas do programa tem um envolvimento muito menor. É possível que este professores percebam os colegas supervisores bolsistas como únicos responsáveis por tudo que envolva o PIBID, acreditando não fazerem parte desta parceria e por isso se distanciando das atividades que ocorrem na escola, ou ainda que não acreditem que as atividades do programa podem beneficiar todos os alunos, e não aqueles dos professores supervisores bolsistas.

O tempo de permanência do PIBID na escola foi algo citado como importante para a maioria dos entrevistados. $76,7 \%$ deles disseram que só depois do quarto trimestre de atuação do PIBID na escola é que o programa começou a contribuir para o estabelecimento ou fortalecimento da parceria entre universidade e escola. Esta parceria é quesito importante para a Capes e o PIBID busca com suas atividades o estabelecimento e fortalecimento deste laço.

\footnotetext{
“Assim, a Capes incentiva as instituições de educação superior a reconhecerem nas escolas públicas um espaço de produção e de apropriação de conhecimento, tornando-as, simultaneamente, partícipes e beneficiárias dos estudos e dos projetos desenvolvidos" (BRASIL, 2011, p. 01).
} 


\section{SEMINÁRIO DE PESQUISA EM CIÊNCIAS HUMANAS - SEPECH \\ Humanidades, Estado e desafios didático-científicos \\ Londrina, 27 a 29 de julho de 2016}

Segundo 46,5\% dos supervisores, a principal contribuição do PIBID foi a valorização da escola pública, com a parceria entre escola básica e universidade sendo apontada por $30 \%$ deles. Ainda em relação a esse grupo, $81,3 \%$ consideram que o PIBID ampliou muito sua capacidade de leitura e escrita de textos e $88,3 \%$ consideram

que os conhecimentos teóricos adquiridos durante a participação no PIBID ajudam muito em sua compreensão, planejamento e desenvolvimento de suas práticas de ensino.

Os alunos das escolas parceiras do PIBID em Uberaba-MG também fizeram parte como sujeitos desta pesquisa. O questionário foi aplicado a 276 alunos, participantes ou não das atividades do PIBID, das mesmas doze escolas públicas em Uberaba onde foram aplicados os questionários com professores e diretores. $\mathrm{O}$ questionário continha 20 perguntas, sendo as quatro primeiras sobre o perfil dos alunos e as restantes sobre a participação destes nas atividades, a relevância delas para a sua formação e a percepção deles sobre a influência do PIBID para valorização do trabalho do(s) professor(es). Os alunos respondentes cursam entre o sétimo ano do ensino fundamental e o terceiro ano do ensino médio, tem faixa etária principalmente entre 12 a 18 anos e se distribuem equilibradamente entre os gêneros.

Dentre os alunos, 94\% consideram que estudam numa boa escola, que a formação que recebem é muito importante e que pretendem cursar uma universidade pública, ecoando as respostas dos professores e diretores. Mais de $75 \%$ deles não pretende ser professor, apesar da maioria afirmar que esta profissão é muito importante para a sociedade e $70 \%$ deles consideram que o PIBID contribui para a valorização do professor. Pode parecer pouco que somente $25 \%$ dos alunos afirmem que pretendem ser professores mas, frente a grande variedade de profissões que eles podem escolher, podemos afirmar que este é um número bastante relevante. $62 \%$ alegam que a profissão de professor traz vantagens e desvantagens e $21 \%$ afirmam que há mais vantagens do que desvantagens.

Mais de $70 \%$ afirmaram ter participado de todas as atividades do PIBID realizadas na escola e que estas são importantes para sua formação. $35 \%$ afirmam que participam das atividades do PIBID há mais de 2 anos e $27 \%$ responderam que participam a mais de um ano e menos de 2, ou seja, os alunos que entram no PIBID gostam da proposta e por isso permanecem por longo período, mostrando interesse pela continuidade das atividades. Para 54\% dos alunos o PIBID contribuiu para que tivessem mais conhecimento a respeito das disciplinas às quais as atividades estavam vinculadas, sendo que só 5\% disseram que não houve contribuição alguma. Para 70\% o PIBID influencia positivamente no interesse pelas disciplinas e igual porcentagem diz que as atividades do programa os motiva aos estudos. A valorização da continuidade dos próprios estudos no ensino técnico e superior foi o principal aspecto que os alunos elencaram como tendo sido influenciado pela sua participação no PIBID.

As respostas sobre o PIBID incentivar ou não o gosto do aluno pela leitura foram bastante equilibradas, sendo que $40,1 \%$ concordaram que o PIBID os influenciou a ler mais enquanto $30,3 \%$ responderam que leem a mesma quantidade que liam antes de participarem das atividades do programa. Ao mesmo tempo $72 \%$ dos alunos consideram que as atividades de escrita do PIBID são importantes para a sua formação. Assim, nos parece que para este grupo de alunos a leitura e escrita não são necessariamente atividades complementares e que o PIBID foi mais efetivo no estímulo à escrita que à leitura, contrariando nossa crença prévia de que as atividades de leitura e escrita 


\section{SEMINÁRIO DE PESQUISA EM CIÊNCIAS HUMANAS - SEPECH \\ Humanidades, Estado e desafios didático-científicos \\ Londrina, 27 a 29 de julho de 2016}

caminhassem juntas e se influenciassem mutuamente, em particular com a leitura auxiliando no desenvolvimento da escrita.

\section{CONSIDERAÇÕES FINAIS}

Os dados apresentados neste trabalho nos permitem afirmar que o PIBID, na visão de diretores, professores e alunos envolvidos no programa, tem impactos majoritariamente positivos para o cotidiano da escola. Para os diretores, a mudança mais significativa é a inclusão de novas atividades no calendário escolar, mudanças na prática docente dos professores supervisores e aumento da motivação e interesse dos alunos pelas aulas, do seu engajamento em atividades e da valorização da escola. Já na percepção dos professores, os impactos positivos do PIBID são percebidos principalmente na mudança de atitudes e comportamento dos alunos participantes e no elevado envolvimento da direção da escola em relação ao PIBID. Com relação à sua atuação no PIBID, os professores supervisores destacam a formação continuada e a possibilidade de participação em eventos científicos como o elementos mais significativos, bem a reflexão sobre sua prática docente motivada pela sua participação nas atividades do programa. De forma geral os professores reconhecem como positiva a contribuição do PIBID na formação dos licenciandos.

Entre os alunos destaca-se o reconhecimento de que o PIBID contribuiu para que eles obtivessem mais conhecimentos nas disciplinas e motivação para os estudos, bem como um aumento no interesse pela continuidade da sua formação em cursos técnicos e superiores.

De forma geral, os dados apresentados acima, ainda que preliminares, nos permitem inferir que, de acordo com a percepção dos sujeitos da escola envolvidos com o PIBID, o programa cumpre seus objetivos de promover a formação continuada e a reflexão dos professores sobre sua prática docente e possibilita a diversificação dos tipos de atividades de ensino desenvolvidas na escola, contribuindo assim para promover o engajamento dos alunos em tais atividades e ampliando a e valorização do ambiente escolar.

Analisando as respostas de professores e alunos não participantes do PIBID nas escolas, podemos perceber que, apesar das significativas contribuições para os seus participantes diretos destacadas anteriormente, a repercussão dessas ações para o resto da comunidade da escola são mais limitadas, sendo seu contato com o PIBID mais esporádico, em geral restrito a momentos de realização de atividades maiores no âmbito escolar. No entanto, a própria estrutura e objetivos do programa, com foco privilegiado na formação inicial de professores de acordo com sua área de formação, privilegia o contato mais próximo com o cotidiano da escola em sua dinâmica curricular e disciplinar. Ainda assim, os informantes dos três segmentos pesquisados destacam a dinamização do cotidiano escolar e a diversificação dos tipos de atividades de ensino como aspectos positivos do programa.

Conjuntamente, os resultados descritos acima permitem afirmar que o PIBID vem criando as condições necessárias para a transformação das representações que alunos e professores participantes fazem de si como sujeitos de conhecimento e, consequentemente, para a transformação nas práticas e relações educacionais, sendo 


\section{SEMINÁRIO DE PESQUISA EM CIÊNCIAS HUMANAS - SEPECH \\ Humanidades, Estado e desafios didático-científicos \\ Londrina, 27 a 29 de julho de 2016}

portanto possível que o programa tenha sucesso em alcançar um dos seus mais ambiciosos objetivos, qual seja o de promover a melhoria da qualidade da educação básica.

\section{REFERÊNCIAS}

BARBOSA, Marinalva. Impactos das Ações do PIBID nas Escolas de Uberaba. Projeto de pesquisa.

CARTA DE UBERABA. IV Encontro Nacional das Licenciaturas - ENALIC e III Seminário nacional do PIBID, 2013. In: BARBOSA, Marinalva V. et. al. (org.) A boniteza de ensinar e a identidade do professor na contemporaneidade. Campinas/SP: Mercado de Letras, 2015. p. 407-411.

BRASIL. Ministério da Educação, Programa Institucional de Bolsas de Iniciação à Docência (PIBID). Disponível em: portal.mec.gov.br/pibid. Acesso em 30/05/2016.

HUBERMAN, Michel. O ciclo de vida profissional dos professores. In: NÓVOA, António (org.). Vidas de professores. Porto: Porto Editora, 1992. p. 31-61.

Instituto Nacional de Estudos e Pesquisas Educacionais Anísio Teixeira (Inep). Disponível em: www.inep.gov.br. Acesso em 30/05/2016.

LIBÂNEO, José C.; OLIVEIRA, João F. de; TOSCHI, Mirza S. Educação escolar: políticas, estrutura e organização. São Paulo: Cortez, 2012.

MINAS GERAIS. Secretaria de Estado da Educação. Sistema Mineiro de Avaliação da Educação Pública - Simave. Disponível em: www.educacao.mg.gov.br. Acesso em 30/05/2016. 